\title{
The Human Innate Immune Protein Calprotectin Elicits a Multimetal Starvation Response in Pseudomonas aeruginosa
}

\author{
Cassandra E. Nelson, ${ }^{a}$ Weiliang Huang, ${ }^{a}$ Emily M. Zygiel, ${ }^{b}$ Elizabeth M. Nolan, ${ }^{b}$ Maureen A. Kane, ${ }^{a}$ (D) Amanda G. Oglesby ${ }^{a, c}$ \\ aDepartment of Pharmaceutical Sciences, School of Pharmacy, University of Maryland, Baltimore, Baltimore, Maryland, USA \\ bDepartment of Chemistry, Massachusetts Institute of Technology, Cambridge, Massachusetts, USA \\ cDepartment of Microbiology and Immunology, School of Medicine, University of Maryland, Baltimore, Baltimore, Maryland, USA \\ Cassandra E. Nelson and Weiliang Huang contributed equally to this article. Author order was determined by a third party.
}

ABSTRACT To combat infections, the mammalian host limits availability of essential transition metals such as iron ( $\mathrm{Fe})$, zinc $(\mathrm{Zn})$, and manganese $(\mathrm{Mn})$ in a strategy termed "nutritional immunity." The innate immune protein calprotectin (CP) contributes to nutritional immunity by sequestering these metals to exert antimicrobial activity against a broad range of microbial pathogens. One such pathogen is Pseudomonas aeruginosa, which causes opportunistic infections in vulnerable populations, including individuals with cystic fibrosis. CP was previously shown to withhold Fe(II) and $\mathrm{Zn}$ (II) from P. aeruginosa and induce Fe and $\mathrm{Zn}$ starvation responses in this pathogen. In this work, we performed quantitative, label-free proteomics to further elucidate how CP impacts metal homeostasis pathways in $P$. aeruginosa. We report that $\mathrm{CP}$ induces an incomplete $\mathrm{Fe}$ starvation response, as many Fe-containing proteins that are repressed by Fe limitation are not affected by CP treatment. The $\mathrm{Zn}$ starvation response elicited by $\mathrm{CP}$ seems to be more complete than the Fe starvation response and includes increases in $\mathrm{Zn}$ transporters and $\mathrm{Zn}$-independent proteins. CP also induces the expression of membranemodifying proteins, and metal depletion studies indicate this response results from the sequestration of multiple metals. Moreover, the increased expression of membrane-modifying enzymes upon CP treatment correlates with increased tolerance to polymyxin $\mathrm{B}$. Thus, the response of $P$. aeruginosa to CP treatment includes both single- and multimetal starvation responses and includes many factors related to virulence potential, broadening our understanding of this pathogen's interaction with the host.

IMPORTANCE Transition metal nutrients are critical for growth and infection by all pathogens, and the innate immune system withholds these metals from pathogens to limit their growth in a strategy termed "nutritional immunity." While multimetal depletion by the host is appreciated, the majority of studies have focused on individual metals. Here, we use the innate immune protein calprotectin (CP), which complexes with several metals, including iron (Fe), zinc $(\mathrm{Zn})$, and manganese $(\mathrm{Mn})$, and the opportunistic pathogen Pseudomonas aeruginosa to investigate multimetal starvation. Using an unbiased label-free proteomics approach, we demonstrate that multimetal withholding by $\mathrm{CP}$ induces a regulatory response that is not merely additive of individual metal starvation responses, including the induction of lipid A modification proteins.

KEYWORDS Pseudomonas aeruginosa, calprotectin, iron, polymyxin B, proteases, zinc

ransition metals are essential for all life, and invading microbial pathogens must acquire these nutrients to grow in the host and cause infection. The host innate immune system limits growth of microbial pathogens by withholding essential transition metals through a strategy termed "nutritional immunity" (1, 2). Metal-sequestering
Citation Nelson CE, Huang W, Zygiel EM, Nolan EM, Kane MA, Oglesby AG. 2021. The human innate immune protein calprotectin elicits a multimetal starvation response in Pseudomonas aeruginosa. Microbiol Spectr 9: e00519-21. https://doi.org/10.1128/Spectrum .00519-21.

Editor Ayush Kumar, University of Manitoba Copyright $\odot 2021$ Nelson et al. This is an open-access article distributed under the terms of the Creative Commons Attribution 4.0 International license.

Address correspondence to Elizabeth M. Nolan, Inolan@mit.edu, Maureen A. Kane, mkane@rx.umaryland.edu, or Amanda G. Oglesby, aoglesby@rx.umaryland.edu.

Received 21 July 2021

Accepted 23 July 2021

Published 22 September 2021 
innate immune proteins are important components of this host response. Nutritional immunity originally focused on the competition for ferric iron [Fe(III)], wherein host proteins such as lactoferrin sequester Fe(III), and bacterial siderophores scavenge Fe(III) from these host proteins and deliver it to bacteria via siderophore receptors (1). Later, with the discoveries of additional metal-sequestering host proteins and microbial metal uptake systems, the model for nutritional immunity expanded to include other nutrient metals, such as manganese $[\mathrm{Mn}(\mathrm{II})]$ and zinc $[\mathrm{Zn}(\mathrm{II})](2,3)$. The $\mathrm{S} 100$ protein calprotectin (CP; S100A8/S100A9 oligomer, MRP8/MRP14 oligomer) plays a central role in nutritional immunity because it sequesters multiple divalent metal ions, including $\mathrm{Mn}$ (II), iron [Fe(II)], nickel [Ni(II)], and $\mathrm{Zn}(\mathrm{II})$ (reviewed in reference 4). CP exerts antimicrobial activity against a broad range of bacterial and fungal pathogens, and this activity is generally attributed to its metal-withholding ability (5-10).

Because the host deploys multiple metal-withholding proteins that coordinate various metal ions (e.g., CP, lactoferrin, siderocalin, and S100A12) at infection sites, bacterial pathogens must respond to the concerted limitation of multiple metal nutrients to cause infection (11). Moreover, bacterial pathogens exhibit various nutritional requirements for transition metals (e.g., some species have a high Fe requirement, whereas others require substantially more $\mathrm{Mn}[12,13])$ and are therefore likely to show speciesand strain-specific responses to host multimetal withholding. Indeed, a recent study of Gram-negative and Gram-positive bacterial pathogens revealed that the effects of CP on the uptake of nutrient metals depend on the organism and the composition of the culture medium (10). Despite the current appreciation for multimetal sequestration by the host, the microbial response to this stress has received relatively less attention than single-metal limitation (11). Because CP sequesters multiple metals, it provides a physiologically important and useful tool for studying the response of microbial pathogens to multimetal withholding by the host.

Pseudomonas aeruginosa is a Gram-negative opportunistic pathogen that causes infections in vulnerable populations, including individuals with cystic fibrosis (CF). $P$. aeruginosa has a high Fe requirement and uses multiple Fe uptake systems to acquire Fe from the host environment, including siderophore-mediated Fe(III) uptake systems, an Fe(II) acquisition system, and heme uptake systems (reviewed in reference 14). Due to the propensity of excess Fe to cause oxidative damage, a complex and hierarchical Fe regulatory system regulates the uptake of Fe in response to cellular Fe concentrations (reviewed in reference 15). This function is mediated by the Fe-binding transcriptional regulator Fur, which in its holo form binds to the promoters of genes encoding Fe uptake systems, thereby blocking their transcription and Fe uptake (16). As Fe levels decrease, Fe dissociates from Fur, and apo-Fur loses affinity for these promoters, allowing transcription of Fur-repressed genes. In addition to Fe uptake genes, Fur also represses the PrrF small regulatory RNAs (sRNAs), which posttranscriptionally repress the expression of nonessential Fe-containing proteins and Fe storage proteins $(17,18)$. This so-called Fe-sparing response reduces the Fe requirement of the cell and is required for $P$. aeruginosa pathogenesis (19-21).

The mechanisms used by $P$. aeruginosa to maintain homeostasis of other transition metals are less well characterized, but several key aspects of select uptake and regulatory systems have been identified. The $\mathrm{Zn}$ (II) homeostasis system in P. aeruginosa includes Zur, a Fur homolog that represses the transcription of $\mathrm{Zn}$ (II) uptake systems (22). P. aeruginosa has several characterized $\mathrm{Zn}$ (II) uptake systems, including the Znu permease, the pseudopaline-metallophore-mediated Cnt (also called Zrm) system, and the HmtA P-type ATPase, as well as putative ABC permease gene clusters (PA2911PA2914 and PA4063-PA4066) (23-26). Repression of Zn(II)-containing proteins has been shown under $\mathrm{Zn}$ (II)-limiting conditions, indicating a $\mathrm{Zn}(\mathrm{II})$-sparing response (23, 26). When $\mathrm{Zn}(\mathrm{II})$ is in excess, transporters, such as the resistance-nodulation-division (RND) pump CzcCBA (27), the cation diffusion facilitator transporters CzcD and ZitB (28), and the P-type ATPase transporter ZntA (29), efflux Zn(II) to prevent toxicity. In terms of $\mathrm{Mn}$ homeostasis, $P$. aeruginosa encodes two predicted $\mathrm{Mn}$ (II) transporters 
(MntH1 and $\mathrm{MntH} 2$ ) (30) and requires $\mathrm{Mn}$ for several Mn-dependent proteins, including the ureohydrolases GbuA and GpuA (31) and the superoxide dismutase SodM (32). However, it remains unclear how this pathogen maintains Mn homeostasis. The copper (Cu) homeostasis system has also been characterized in $P$. aeruginosa and is composed of Cu importers, Cu chaperones, and Cu efflux pumps to maintain Cu homeostasis (33).

$\mathrm{CP}$ is found in high concentrations in the lungs of CF patients, which are commonly infected by $P$. aeruginosa (34-36). Moreover, CP has been shown to reduce the antimicrobial activity of $P$. aeruginosa toward another CF pathogen Staphylococcus aureus, which was attributed to its ability to inhibit the production of toxic secondary metabolites by $P$. aeruginosa, including phenazines and 2-alkyl-4(1H)-quinolones (AQs) (37). We previously reported, using targeted analyses of known Fe acquisition and regulatory systems, that CP withholds Fe from $P$. aeruginosa and thereby causes an Fe starvation response (10). Our study also demonstrated a change in virulence factor production in response to $\mathrm{CP}$ with the downregulation of phenazines, which we determined to be a consequence of Fe limitation (10). Moreover, a recent investigation demonstrated that CP withholds $\mathrm{Zn}(\mathrm{II})$ from $\mathrm{P}$. aeruginosa and induces a $\mathrm{Zn}$ starvation response (38). This study also reported decreased $Z n(I I)$ protease activity caused by CP, indicating attenuated virulence potential. Because previous studies on the impact of $\mathrm{CP}$ on $P$. aeruginosa have focused on a single metal, we sought to determine the response of $P$. aeruginosa to multiple metal withholding by $C P$.

In this work, we investigated how CP-dependent metal depletion affects $P$. aeruginosa physiology and virulence capacity using quantitative, label-free proteomics. In agreement with prior studies $(10,38)$, our analyses show that CP causes both Fe and $Z n$ starvation responses in $P$. aeruginosa. Moreover, we identified increases in the expression of $\mathrm{Zn}(\mathrm{II})$-containing proteases and membrane-modifying enzymes in response to $\mathrm{CP}$. To decipher whether the observed changes in protein expression resulted from single-metal or multimetal sequestration by $\mathrm{CP}$, we used our proteomics workflow to evaluate the consequences of $\mathrm{Fe}, \mathrm{Mn}$, and $\mathrm{Zn}$ limitation on the $P$. aeruginosa proteome. This effort revealed that $\mathrm{CP}$ elicits an expected $\mathrm{Zn}$ starvation response and what appears to be an incomplete Fe starvation response. Moreover, CP treatment leads to the induction of membrane-modifying enzymes, likely as a consequence of multimetal sequestration. This response correlated with increased tolerance to polymyxin $B$, suggesting that host metal sequestration may induce $P$. aeruginosa tolerance to cationic antimicrobial peptides (CAMPs). Together, this work shows that the response of $P$. aeruginosa to multimetal withholding by $C P$ is distinct from that of single-metal withholding and suggests a complex microbial response to this innate immune protein.

\section{RESULTS}

$\mathrm{CP}$ causes $\mathrm{Fe}$ and $\mathrm{Zn}$ starvation responses and alters virulence protein production in $\boldsymbol{P}$. aeruginosa. To determine the global response of $P$. aeruginosa to $C P$, we evaluated the impact of $10 \mu \mathrm{M} \mathrm{CP}$ treatment on the PA14 proteome. PA14 was grown under conditions that were previously used to study the consequences of CP treatment on $P$. aeruginosa and other pathogens $(10,39)$. Specifically, PA14 was cultured under aerobic conditions in a metal-replete chemically defined medium (CDM) containing $2 \mathrm{mM}$ calcium (Ca), $5 \mu \mathrm{M}$ Fe, $0.3 \mu \mathrm{M} \mathrm{Mn}, 6 \mu \mathrm{M} \mathrm{Zn}, 0.1 \mu \mathrm{M} \mathrm{Ni}$, and $0.1 \mu \mathrm{M} \mathrm{Cu}$ in the presence or absence of $10 \mu \mathrm{M} \mathrm{CP}$. These metal concentrations were selected to be within the reported range of metal levels in the sputa of CF patient samples (40-42), and the concentration of $\mathrm{CP}$ is within the range of $\mathrm{CP}$ concentrations in samples of sputa from CF patients (8 $\mu \mathrm{M}$ to $40 \mu \mathrm{M}$ CP heterodimer) (43). We selected CDM for these studies because it allows for control over the metal concentrations and sources (e.g., nonheme versus heme Fe), and it is amino acid rich, similar to what is found in CF sputum (44). Prior whole-cell metal analyses in metal-replete CDM revealed that treatment of PA14 with $\mathrm{CP}$ results in a significant decrease in cell-associated Fe and negligible change in cell-associated Mn, Ni, Cu, and Zn (45). PA14 was grown for 8 h, which afforded growth to early stationary phase (10). Cells were harvested, and quantitative 
label-free proteomics was performed using nano ultraperformance liquid chromatography coupled to high-resolution tandem mass spectrometry as previously described (46-48). Protein levels that were significantly $(P<0.05, n=5)$ changed at least 2-fold (equivalent to $1 \log _{2}$ fold change [LFC]) were analyzed further.

$\mathrm{CP}$ treatment caused a significant increase in the abundance of 93 proteins and a significant decrease in the abundance of 72 proteins (Fig. 1A; Table S1 in the supplemental material). To identify biological connections within the upregulated and downregulated proteins, we performed network analyses using the search tool for the retrieval of interacting genes/proteins (STRING) database (49), which generates a map to visualize the biological connections between proteins that were up- or downregulated. The proteins are represented by nodes and connected by edges, and the thickness of the edges represents the amount of associations based on known and predicted interactions, text mining, coexpression, and protein homology. The networks created for proteins that were downregulated (Fig. 1B; Table S1) or upregulated (Fig. 1C; Table S1) following $\mathrm{CP}$ treatment showed significantly more interactions than if they were a random collection of genes from the genome, indicating a biological relationship between the proteins in each analysis (Table S2). In agreement with recent studies showing that $C P$ induces an Fe starvation response in $P$. aeruginosa $(10,45)$, proteins involved in pyoverdine-mediated Fe(III) uptake, in the Feo Fe(II)-import system, and in heme-dependent $\mathrm{Fe}$ acquisition were upregulated in response to $\mathrm{CP}$, whereas proteins involved in phenazine biosynthesis (PhzE, PhzD, $\mathrm{PhzC}, \mathrm{PhzM}$, and $\mathrm{PhzH}$ ) and secretion (MexH and Mexl) were downregulated (Fig. S1). CP treatment also resulted in an apparent Fe-sparing response, indicated by the downregulation of nonessential Fe-containing proteins. For example, nonessential Fe- and heme-containing proteins, such as LeuC and KatA, were downregulated upon CP treatment, whereas the Fe-independent paralog of fumarase (FumC1) and the Mn-dependent superoxide dismutase (SodM) were upregulated in response to $\mathrm{CP}$ (Fig. S1). However, CP treatment did not reduce levels of several Fe-containing tricarboxylic acid (TCA) cycle proteins, which were previously shown to be repressed by the PrrF sRNAs as a part of the $P$. aeruginosa Fe-sparing response $(17,18,50,51)$.

Consistent with a recent study (38), CP-treated cells showed a robust $\mathrm{Zn}$ starvation response. This response included increased levels of proteins for $\mathrm{Zn}$ (II) uptake systems, including ZnuACD and proteins for the synthesis and uptake of pseudopaline (CntM and $\mathrm{CntO}$, respectively) $(22,25,26)$. CP treatment also led to an increase in several predicted Zn(II) uptake proteins (PA4063-PA4066, PA2912-PA2914, PA1921, and PA1922) that were shown in a previous transcriptomic study to be induced by $\mathrm{Zn}$ starvation (25, 26). Also consistent with the previously described $\mathrm{Zn}$ starvation response (23), $\mathrm{Zn}(\mathrm{II})$ containing proteins RpmE and RpmJ were downregulated, and $\mathrm{Zn}$ (II)-independent proteins RpmE2, DksA2, and PyrC2 were upregulated following CP treatment (Fig. S3). Despite the robust $\mathrm{Zn}$ starvation response to $\mathrm{CP}$ observed here and in previous work (38), only negligible changes in cell-associated $\mathrm{Zn}$ levels were observed for PAO1 and PA14 grown in metal-replete CDM supplemented with $10 \mu \mathrm{M} \mathrm{CP}(10,45)$.

Although CP has the ability to withhold Mn, levels of known Mn cofactored proteins (HutG, Gpml, and UbiD) and predicted Mn uptake proteins (MntH1 and MntH2) in PA14 were not significantly affected by CP treatment. Prior work revealed that the ability of CP to reduce cell-associated $\mathrm{Mn}$ in $P$. aeruginosa is medium dependent $(10,45)$. Whereas CP treatment reduced cell-associated Mn levels when PA14 and PAO1 were grown in a mixture of Tris buffer and tryptic soy both (Tris:TSB) (10), a negligible change in cell-associated Mn was observed when these strains were treated with CP in metal-replete CDM (45). This medium effect may explain the lack of a putative Mn starvation response in this proteomics analysis. As noted above, the Mn-dependent superoxide dismutase SodM was upregulated in response to $\mathrm{CP}$, possibly resulting from an Fe starvation response.

In addition to known Fe- and Zn-responsive proteins, proteins for the type VI secretion system (T6SS) (Lip2.1, HsiC2, and HcpC), motility and chemotaxis (Aer, Chew2, 

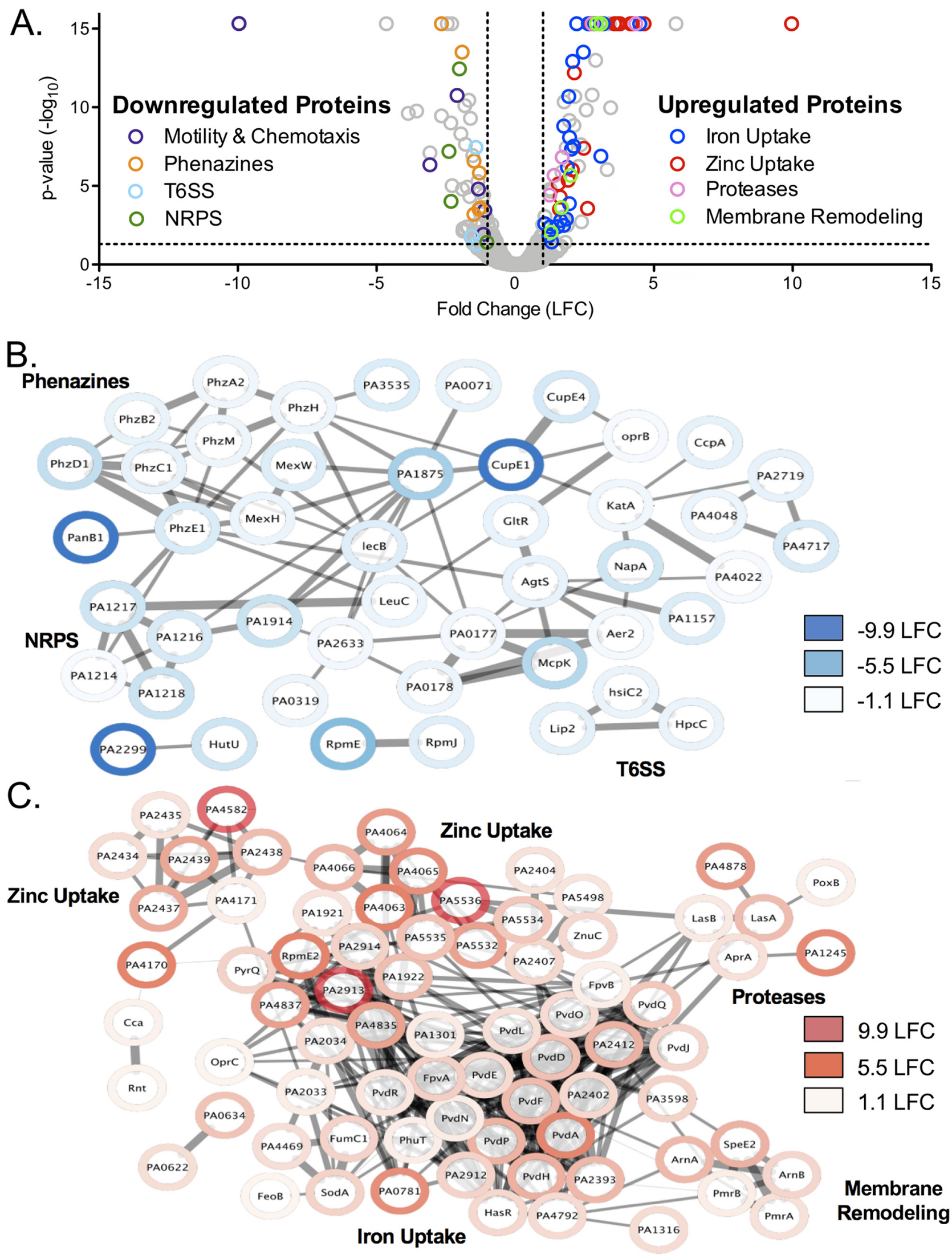

FIG 1 Proteomic analysis of $P$. aeruginosa response to CP. (A) Volcano plot of PA14 response to CP treatment. Every protein detected in the experiment is represented by an open, gray circle. Circles representing significantly regulated proteins in functional categories of interest are 
CheA2, FlgA, CupE2, and CupE4), and a nonribosomal peptide synthetase (NRPS) of unknown function (PA1214, PA1216, PA1217, and PA1218) were downregulated following $\mathrm{CP}$ treatment (Fig. 1; Table S1). CP treatment also led to the upregulation of proteins involved in membrane remodeling and tolerance to CAMPs (PmrA, PmrB, ArnA, ArnB, and SpeE2). Curiously, CP treatment caused an increase in several Zn(II)-dependent metalloproteases (ImpA, AprA, LasA, and LasB), contrasting with the Zn-sparing response described above. Altogether, this proteomics analysis indicates that $C P$ exposure induces both Fe and $\mathrm{Zn}$ starvation responses by $P$. aeruginosa and alters the expression of proteins involved in several virulence processes.

$\mathrm{CP}$ elicits $\mathrm{Fe}$ and $\mathrm{Zn}$ starvation responses that are distinct from single-metal limitation. We next evaluated whether the changes in protein expression described above for CP-treated PA14 resulted from sequestration of an individual metal, multimetal sequestration, or a metal-independent response to $C P$ using the same quantitative proteomics workflow. We focused these analyses on the limitation of $\mathrm{Mn}, \mathrm{Fe}$, and $\mathrm{Zn}$ since the ability of $\mathrm{CP}$ to sequester $\mathrm{Mn}(\mathrm{II}), \mathrm{Fe}(\mathrm{II})$, and $\mathrm{Zn}(\mathrm{II})$ and induce microbial responses to the limitation of these metal nutrients is established $(7,10,52)$. For these experiments, CDM was prepared in the absence of either $\mathrm{Fe}, \mathrm{Mn}$, or $\mathrm{Zn}$ or was lacking all three metals to afford "Fe-depleted," "Zn-depleted," "Mn-depleted", and "metaldepleted" CDM, respectively, and protein abundance was compared to that of PA14 grown in metal-replete CDM. A network analysis was used as described above to determine biological connections within the upregulated and downregulated proteomes in response to $\mathrm{Fe}, \mathrm{Zn}$, and $\mathrm{Mn}$ limitation (Table S1).

The Fe starvation response observed following growth in Fe-depleted CDM was consistent with the well-known regulatory response of $P$. aeruginosa to Fe limitation $(17,50,51)$ (Fig. S1), despite the use of a lower Fe concentration in the metal-replete condition (5 $\mu \mathrm{M}$ instead of $100 \mu \mathrm{M}$ ), a chemically defined medium (CDM instead of Chelex-treated and dialyzed TSB [DTSB]), a different time point (early instead of late stationary phase), and a different strain of $P$. aeruginosa (PA14 versus PAO1). Specifically, Fe limitation resulted in the downregulation of Fe-containing TCA cycle enzymes (SdhBAC, AcnA, PA0794, and PA4330), a putative bacterioferritin (PA4880), and Fe-containing oxidative stress response proteins ( $\operatorname{SodB}$ and $\operatorname{Kat} A$ ), the upregulation of Fe-independent homologs of TCA cycle enzymes (MqoA and FumC1) and a superoxide dismutase (SodM), and the upregulation of pyoverdine- and heme-dependent Fe uptake systems. When PA14 was grown in Zn-depleted CDM, a Zn starvation response was observed that was consistent with the transcriptomic response to $\mathrm{Zn}$ limitation and investigation of $\mathrm{Zn}$ (II) uptake mutants described in previous investigations (Fig. S2) $(25,26)$. Specifically, we observed the downregulation of $\mathrm{Zn}$ (II)-containing proteins (RpmE and RpmJ) and the upregulation of $\mathrm{Zn}(\mathrm{II})$-independent paralogs of $\mathrm{Zn}$ (II)-containing proteins (RpmE2, DksA2, PyrC2, CynT2, and FolE2). CP treatment also led to upregulation of proteins for the biosynthesis and transport of pseudopaline (CmtM, CmtL, and CmtO), ZnuABC, the Zn(II)-responsive HmtA heavy metal transport system, and several predicted Zn(II) uptake systems (PA4063-PA4066, PA2912-2914, and PA1921). These results demonstrate that the growth conditions used here and in previous studies to investigate CP (10) allow for characteristic $P$. aeruginosa Fe and $\mathrm{Zn}$ starvation responses.

When PA14 was grown in Mn-depleted CDM, we found no evidence for a putative $\mathrm{Mn}$ starvation response. The predicted $\mathrm{Mn}(\mathrm{II})$ transporters $\mathrm{MntH} 1$ and $\mathrm{MntH} 2$ were not significantly upregulated in Mn-depleted CDM, and neither known nor predicted

FIG 1 Legend (Continued)

highlighted with the colors indicated in the legend. The thresholds for significance $(P<0.05)$ and expression $\left(1\right.$ log fold $_{2}$ change $[\mathrm{LFC}$, equivalent to a 2 -fold change) are marked by a black dashed line. Proteomics was performed with an $n$ of 5 , and significance was determined by an ANOVA test corrected for multiple testing by applying a Benjamini-Hochberg procedure (84). (B, C) Network analysis was performed using the STRING database (49) on the proteins that were significantly downregulated (B) and upregulated (C) in response to $C P$ treatment. The thickness of lines between proteins indicates the strength of the data supporting the interaction, with more data correlating to a thicker line. The network was transferred into Cytoscape (79), and proteomics expression data were integrated using the Omics Visualizer app (80). 


\section{A. Downregulated Proteins}

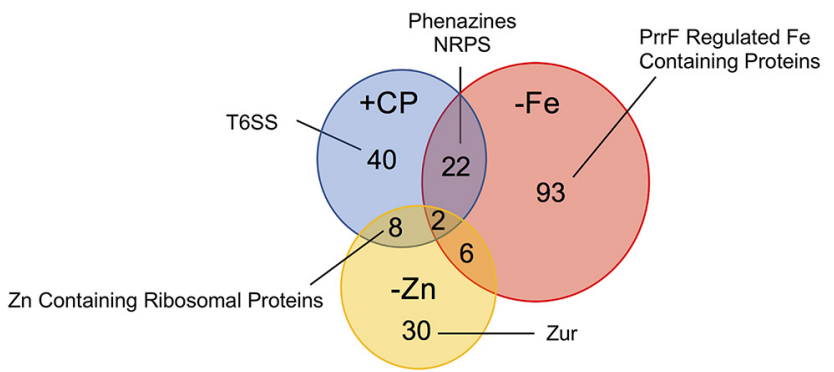

\section{B. Upregulated Proteins}

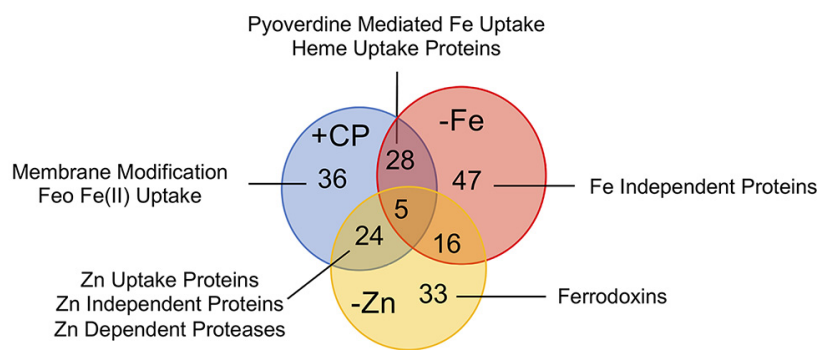

FIG 2 Comparison of the proteome in response to $\mathrm{Fe}$ and $\mathrm{Zn}$ limitation and $\mathrm{CP}$ treatment. Venn diagrams of significantly $(P<0.05)$ downregulated $(>1$ LFC) (A) and upregulated $(>1$ LFC) (B) proteins in response to $\mathrm{CP}$ treatment $(+\mathrm{CP})$, Fe limitation $(-\mathrm{Fe})$, and $\mathrm{Zn}$ limitation $(-\mathrm{Zn})$. Proteomics was performed with an $n$ of 5 ; LFC, $\log _{2}$ fold change.

Mn-containing proteins were downregulated beyond the established LFC threshold (30). We noted a significant downregulation of SodM, although the fold change in this protein was below our threshold of 1 LFC (0.8 LFC). Additionally, there was no significant biological connection between the upregulated or downregulated proteins identified by network analysis (Table S2). Because no robust Mn starvation response was observed following either Mn limitation or CP treatment, we focused the remainder of our metal depletion studies on Fe and Zn.

We next identified overlaps in the proteomic responses to CP treatment, Fe limitation, and $\mathrm{Zn}$ limitation. We observed an $\sim 35 \%$ overlap between proteins upregulated by $\mathrm{CP}$ treatment and Fe limitation, including proteins involved in the uptake of $\mathrm{Fe}(\mathrm{III})$ pyoverdine and heme (Fig. 2B; Table S3). Proteins that were observed to be upregulated by Fe limitation but not CP treatment included several Fe(III) uptake proteins that were either not detected in the CP treatment experiment (8 proteins) or not significantly upregulated beyond the 1 LFC threshold (PhuR). Approximately $20 \%$ of the proteins that were downregulated in response to Fe limitation were also downregulated in response to CP (Fig. 2; Table S3). These proteins included phenazine biosynthesis and secretion proteins and the NRPS operon noted above. Further analysis of the 99 downregulated proteins that appeared specific to Fe limitation revealed that 9 of these proteins were significantly $(P<0.05)$ downregulated following $C P$ treatment, but the change did not meet the 1 LFC threshold, possibly indicating a weaker Fe starvation response to $C P$ than induced by Fe-depleted CDM (Fig. S1). Notably, several PrrF regulon proteins, including TCA cycle enzymes (SdhABCD and AcnB), NADH dehydrogenase (NuoABCEFGHI), and the putative bacterioferritin (PA4880), were not significantly changed in the presence of $C P$, indicating that $C P$ treatment elicits an incomplete Fesparing response. Previous studies using an AntR transcriptional and translational reporter strain showed that AntR, which is downregulated by PrrF during growth in DTSB (53), is also downregulated in response to CP treatment during growth in Tris: TSB (10). However, AntR and its regulatory targets AntABC were not detected in this proteomics experiment. To determine whether the Fe starvation response to $\mathrm{CP}$ during growth in metal-replete CDM included a decrease in AntR, we used the same reporter 
strain and found that ant $R$ expression is similarly repressed by $\mathrm{CP}$ treatment during growth in metal-replete CDM (Fig. S2), indicating that PrrF functions under these conditions. Combined, these data indicate that that CP elicits only a portion of the Fe starvation response that is observed following Fe limitation in Fe-depleted CDM.

The shared response to both $\mathrm{Zn}$ limitation and CP treatment was consistent with the known $\mathrm{Zn}$ starvation response and included the downregulation of $\mathrm{Zn}$ (II)-containing ribosomal proteins (RpmJ and RpmE) (Fig. 2A; Fig. S3) and the upregulation of Znu transport proteins (ZnuA and ZnuC), pseudopaline biosynthesis and transport (CntM and CntO) proteins, the $\mathrm{Zn}(\mathrm{II})$-independent ribosomal protein RpmE2, and the $\mathrm{Zn}(\mathrm{II})$-independent paralog to DksA, DksA2 (Fig. 2B; Fig. S3). Notably, several Zn(II)-dependent proteases (LasA, LasB, ImpA, and AprA) were upregulated by both $\mathrm{CP}$ and $\mathrm{Zn}$ (II) limitation, seemingly contrary to the observed $\mathrm{Zn}$ starvation response and a recent report on decreased protease activity in response to $\mathrm{CP}$ (38) (Fig. 2B). The upregulated proteins that were specific to the $\mathrm{Zn}$ limitation proteome included $\mathrm{Zn}$ (II)-independent proteins (CynT2 and FolE2) that were not significantly changed in response to CP. Moreover, two ferredoxins ( $F d x 2$ and $F d x A$ ) were upregulated by $\mathrm{Zn}$ limitation and were not significantly affected by CP treatment (Table S3). Notably, the Zn(II)-responsive transcriptional regulator Zur was downregulated only in response to $\mathrm{Zn}$ limitation. Previous work demonstrated that zur is cotranscribed with znuC and $z n u B$, and expression of all three genes is induced by Zn limitation (Fig. S4A) (22). However, in the current work, Zur was downregulated by Zn limitation and unchanged in response to $C P$, whereas $Z n u C$ and $Z n u B$ were upregulated in both the $Z n$-depleted and CP treatment conditions (Fig. S4B). We performed real-time PCR (RT-PCR) analysis to investigate this finding further and observed that expression of both the znuA and zur mRNAs were induced by CP treatment and by Zn limitation (Fig. S4C and D), suggesting that Zur is posttranscriptionally downregulated following $\mathrm{Zn}$ limitation and CP treatment. Together, these observations suggest that the response of $P$. aeruginosa to $Z n$ starvation is more complex than currently appreciated; this notion warrants further investigation.

The comparisons between the responses of PA14 to CP, Fe limitation, and Zn limitation also identified responses that were unique to CP treatment. Several T6SS proteins encoded by the HSI-II T6SS locus (Fig. 2A and 3A) were downregulated only in response to CP. This result was surprising given that our recent proteomic studies showed that Fe starvation upregulates the expression of the same T6SS proteins (46). However, the mRNAs encoding three of the HSI-II T6SS proteins (lip2, clipV2, and hsiB2) were not significantly changed in a subsequent RT-PCR experiment (Fig. $3 B$ to D), contrasting with a recent Fe regulation study (46) and the current proteomics results (Fig. 3A). The difference in gene expression between this work and the previous study may result from differences in experimental conditions, and posttranscriptional effects may be responsible for the distinct effects of CP on protein expression. Also notable was the Feo Fe(II) import system, which was upregulated only in response to $C P$ but not in response to Fe limitation (Fig. 2A; Fig. S1). Additionally, proteins involved in membrane modification and CAMP tolerance (PmrA, PmrB, ArnA, ArnB, and SpeE2) were upregulated only in response to CP (Fig. 2B; Table S3). The Feo Fe(II) transport system has been shown to be regulated by PmrAB (54), possibly explaining the increase in its expression in response to $\mathrm{CP}$. Together, these data indicate that CP treatment elicits a physiological response that overlaps with, but is distinct from, the $P$. aeruginosa Fe and $\mathrm{Zn}$ starvation responses.

CP treatment and $\mathrm{Zn}$ limitation reduces LasB activity despite increases in protease levels. The observed increase in the levels of secreted proteases (LasB, LasA, AprA, and ImpA) in response to $\mathrm{Zn}$ limitation and $\mathrm{CP}$ treatment (Fig. $4 \mathrm{~A}$ ) was surprising for several reasons. First, these proteases are secreted proteins, and our workflow was designed to analyze the cell-associated proteomes of $P$. aeruginosa. Second, a previous study demonstrated decreased LasB activity under Zn-limiting conditions (26), and more recent work showed a similar decrease in protease activity upon chelation of $\mathrm{Zn}$ (II) by CP (38). To investigate this finding further, we quantified LasB activity against azocasein of PA14 grown in metal-replete, Fe-depleted, Zn-depleted, Mn-depleted, and metal-depleted CDM or in the presence of CP. In contrast to what was observed with cell-associated protease levels and in agreement with previous studies $(26,38)$, LasB 


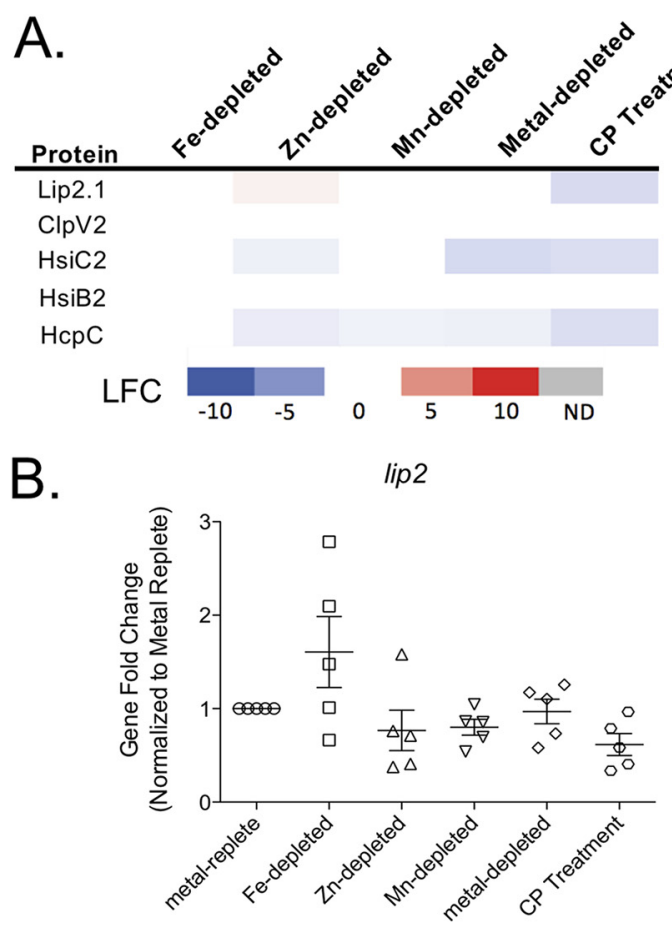

C.

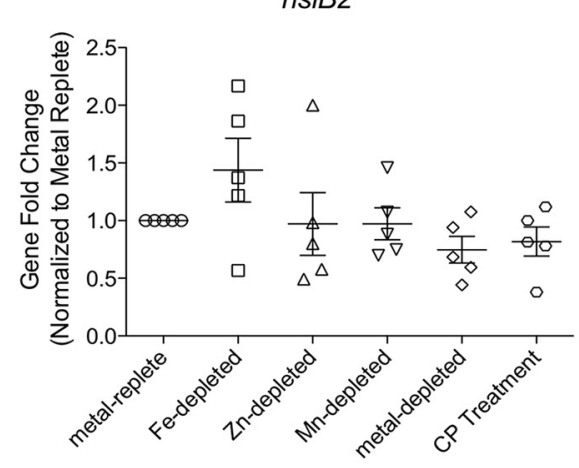

D.

$c / p V 2$

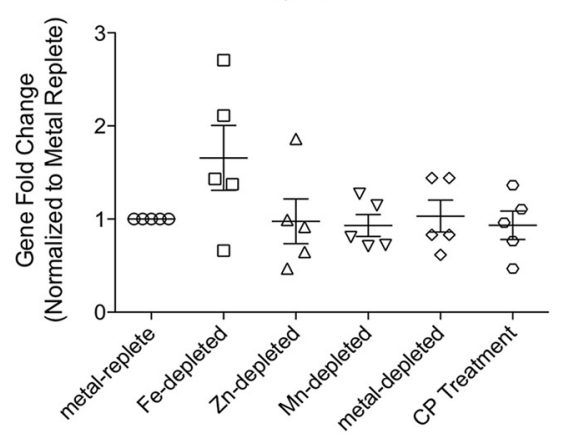

FIG 3 T6SS proteins are downregulated in response to CP. (A) Heat map of protein expression of $P$. aeruginosa PA14 grown in Fe-depleted, Zn-depleted, Mn-depleted, metal-depleted CDM, and metalreplete CDM in the presence of CP compared to expression in metal-replete CDM. The $\log _{2}$ fold change (LFC) is shown for all significantly $(P<0.05)$ changed proteins. Gene expression under the same conditions was measured for lip2 (B), hsiB2 (C), and clpV2 (D) using RT-PCR. No significance was detected in any of the comparisons. Significance was determined by one-way ANOVA with Dunnett's multiple-comparison test $(n=5)$. 

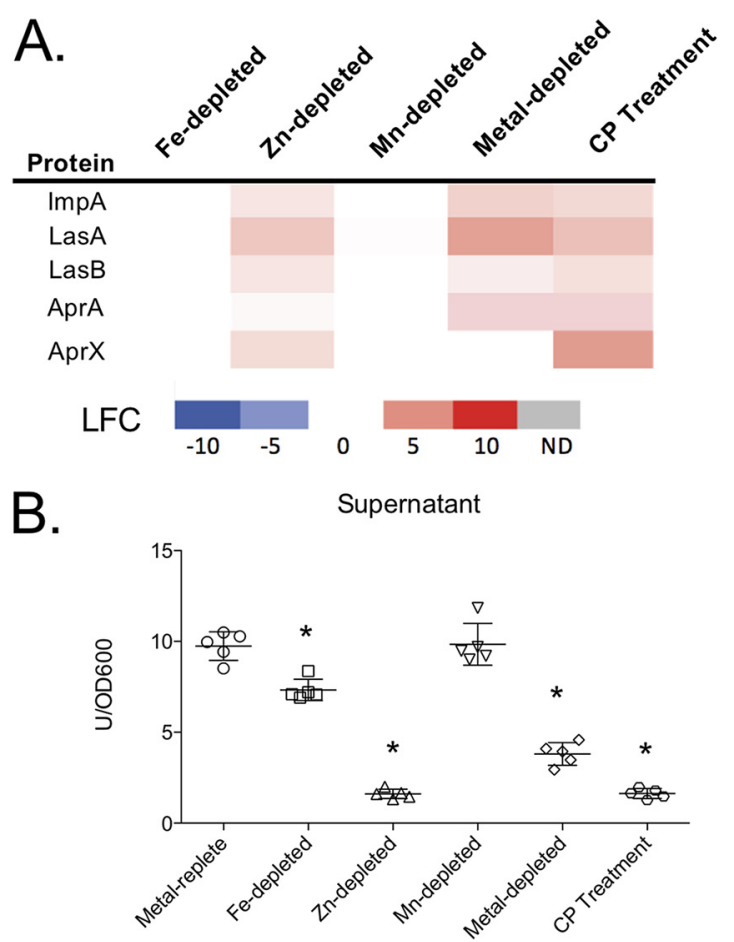

C.

Supernatant $+10 \mu \mathrm{M} \mathrm{Zn}(\mathrm{II})$

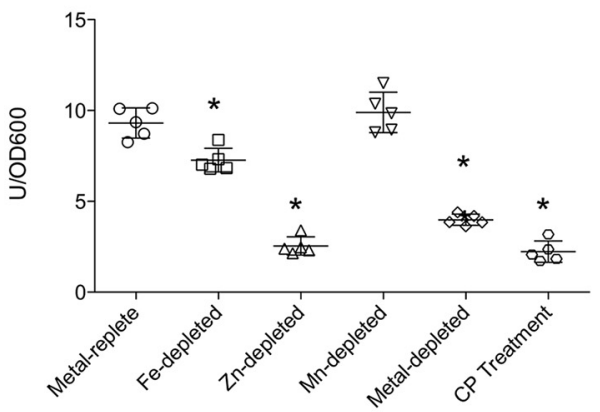

D.

Cell Pellet

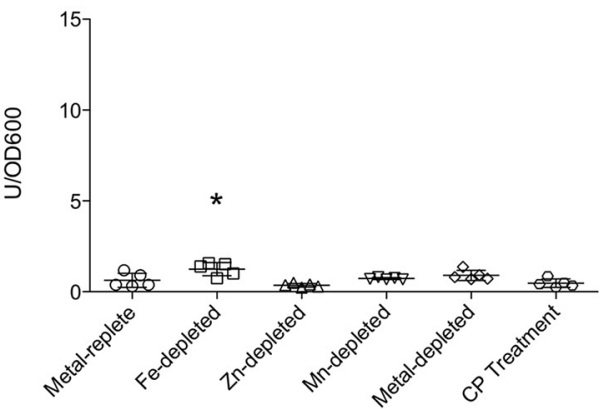

FIG 4 LasB activity decreased in response to $\mathrm{Zn}$ limitation despite an increase in cell-associated protein abundance. Heat map (A) of secreted proteases shown for all experimental conditions compared to the metal replete control. The $\log _{2}$ fold change (LFC) of significantly $(P<0.05)$ changed proteins is shown for selected proteins. LasB activity was measured in the supernatant in the absence (B) and presence (C) of $10 \mu \mathrm{M} \mathrm{Zn(II)} \mathrm{in} \mathrm{the} \mathrm{assay} \mathrm{buffer} \mathrm{to} \mathrm{determine} \mathrm{if} \mathrm{activity} \mathrm{could} \mathrm{be} \mathrm{restored.}$ LasB activity of the cell lysate (D) was also determined. Activity was determined by azocasein assay and normalized to $\mathrm{OD}_{600}$ after $8 \mathrm{~h}$ of growth. Significance was determined by one-way ANOVA with Dunnett's multiple-comparison test; $n=5 ;{ }^{*}, P<0.05$. 
activity in the culture supernatants decreased following both $\mathrm{Zn}$ limitation and $\mathrm{CP}$ treatment (Fig. 4B). A previous study with PAO1 reported the restoration of LasB activity in $\Delta z n u A$ and $\Delta c n t O \mathrm{Zn}$ (II) uptake mutants with the addition of $\mathrm{Zn}$ (II) to the assay buffer but not in $\Delta z n u A \Delta c n t O$ mutants (26). Similar to the $\Delta z n u A \Delta c n t O$ mutant, we were unable to recover LasB activity to $\mathrm{Zn}$-depleted or CP-treated culture supernatants by supplementing the assay buffer with $\mathrm{Zn}$ (II) (Fig. 4C). The $\Delta z n u A \Delta c n t O$ double mutant had a marked growth defect during growth in minimal medium and significantly lower cell-associated $\mathrm{Zn}$ than wild-type cells and single mutants, indicating that it was more $\mathrm{Zn}$ starved than the single mutants (26). One possible explanation is that the $\mathrm{Zn}$ depleted and CP-treated cultures were similarly too $\mathrm{Zn}$ starved to recover protease activity with the addition of $\mathrm{Zn}$ (II) to the assay buffer. An alternative explanation is that, under our culture conditions, the proteases were not secreted, which is supported by the increase in these proteins in the cell-associated proteome.

To determine if the decrease in secreted protease activity following $\mathrm{Zn}$ limitation or $\mathrm{CP}$ treatment was due to decreased secretion of the proteases, we determined whether a corresponding increase in LasB activity was observed in these cell lysates. We noted a small but statistically significant increase in protease activity in cell lysates from the Fe-depleted condition compared to lysates from the metal-replete condition (Fig. 4D). However, no change was noted in lysates from the $\mathrm{Zn}$ limitation or CP treatment conditions. There is currently some debate in the literature on whether LasB is secreted in its inactive proform or activated in the periplasm, but a recent study indicates that LasB is activated after secretion (55). Thus, these data do not necessarily refute the hypothesis that decreased protease activity is due to decreased secretion.

To further investigate the hypothesis that secretion of proteases is decreased in response to $\mathrm{Zn}$ limitation, we considered that the expression of secretory systems responsible for export of each of these proteases may be downregulated under these conditions. LasA, LasB, and ImpA are secreted by the Xcp and Hxc type II secretion systems (T2SS) (56, 57), whereas the alkaline protease AprA is secreted by a type I secretion system (T1SS) encoded by the aprDEF operon upstream of the aprA gene (58). Among the proteins for each of these systems, our proteomics data showed that only two proteins (XcpX and AprF) were downregulated following CP treatment. Upon Zn limitation, XcpX was not significantly changed, and AprF was downregulated below our threshold of 1 LFC (Fig. S5A). In contrast, $\mathrm{HxcV}$ was strongly repressed when PA14 was cultured in Zn-depleted medium. This protein was not detected in the CP-treated samples; thus, we cannot exclude the possibility that CP similarly repressed its expression. Further gene expression analysis showed that expression of xcpT did not change following CP treatment or Zn limitation, whereas $x c p P$ expression increased a small but statistically significant amount in response to both CP treatment and Fe limitation (Fig. S5B and C). Similarly, expression of genes within the $x c p$ operons was not significantly changed under any condition tested (Fig. S5D to G). Overall, these data suggest that decreased expression of proteins that secrete $\mathrm{Zn}$ (II)-dependent proteases is unlikely to contribute to the decreased LasB activity in culture supernatants despite increased levels of these proteins within cells.

CP treatment increases levels of membrane-remodeling proteins. As mentioned above, $C P$ treatment resulted in increased expression of the two-component regulator PmrAB and its regulatory targets ArnA and ArnB, which synthesize aminoarabinose and the spermidine synthetase SpeE2 (Fig. 5A) $(59,60)$. The addition of spermidine to lipopolysaccharide (LPS) and aminoarabinose to lipid A promotes tolerance to CAMPs, including colistin (polymyxin E) and polymyxin B (59-62). The literature refers to an increase in resistance to CAMPs; however, the change in susceptibility is transient and in response to the environment, hence, we have used tolerance (63). Initially, it appeared that the induction of membrane-remodeling machinery did not overlap with the Fe or $\mathrm{Zn}$ starvation responses and therefore may be part of a metal-independent response. Further analysis, however, showed that $\mathrm{Zn}$ limitation caused a small but significant increase in SpeE2 that fell below our initial LFC threshold of 1 (0.6 LFC). Moreover, SpeE2, ArnB, and PmrA were significantly upregulated in metal-depleted CDM, suggesting that this CP-induced 


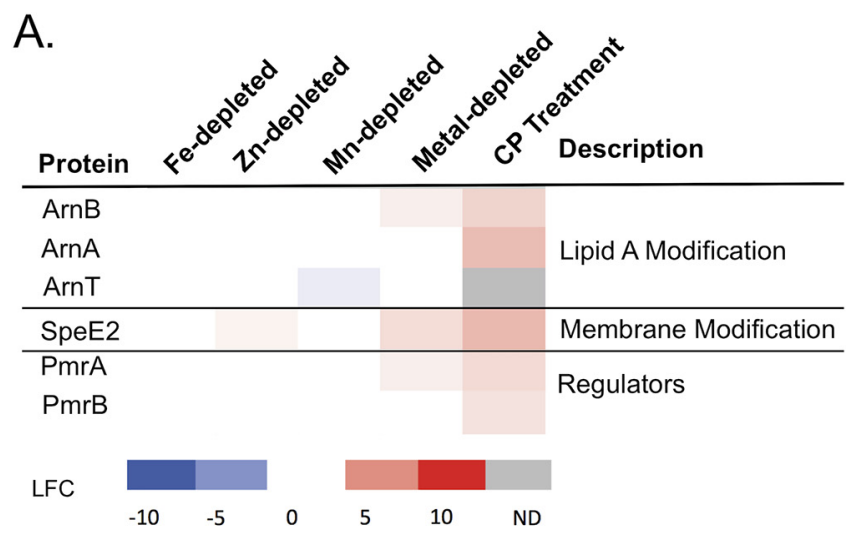

B. Polymyxin B MBC

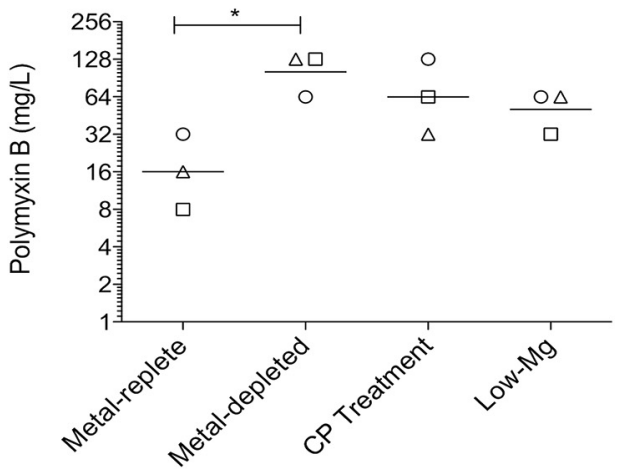

FIG 5 Polymyxin B tolerance increases after exposure to CP. (A) Heat map of membrane-remodeling proteins under all metal depletion conditions. Protein expression is compared to the metal-replete condition. The $\log _{2}$ fold change (LFC) of each significantly $(P<0.05)$ changed protein is shown. (B) The minimal bactericidal concentration (MBC) of polymyxin $B$ was determined for PA14 after preculture in metal-replete, metal-depleted, and low-Mg(II) CDM and after CP treatment. The geometric mean of the three biological replicates for each condition is denoted with a line. The biological replicates are represented with circles (replicate 1), squares (replicate 2), and triangles (replicate 3). Significance was determined by one-way ANOVA with Dunnett's posttest; ${ }^{*}, P<0.05$.

response resulted from multimetal sequestration. To investigate whether $\mathrm{CP}$ treatment afforded CAMP tolerance in P. aeruginosa, we evaluated how CP pretreatment of PA14 affected the minimal bactericidal concentration $(\mathrm{MBC})$ of polymyxin $\mathrm{B}$. Because previous studies demonstrated increased polymyxin B tolerance after growth under low-Mg(II) conditions that results from aminoarabinose modification of lipid A (54), PA14 was also precultured in metal-replete CDM supplemented with $20 \mu \mathrm{M} \mathrm{Mg}$ (II) (low-Mg CDM), instead of the standard $2 \mathrm{mM} \mathrm{Mg}(\mathrm{II})$, as a positive control. Although we noted some variation in MBCs between three biological replicates, bacteria precultured in metal-replete CDM were consistently less tolerant to polymyxin $B$ than bacteria precultured in metal-replete, lowMg CDM (Fig. 5B; Table S4). PA14 precultured in either metal-depleted CDM or pretreated with $\mathrm{CP}$ exhibited $\mathrm{MBC}$ ranges (64 to $128 \mathrm{mg} / \mathrm{liter}$ and 32 to $128 \mathrm{mg} / \mathrm{liter}$, respectively) that overlapped with that of the cultures grown in low-Mg CDM (32 to $64 \mathrm{mg} / \mathrm{liter}$ ). Statistical significance $(P<0.05)$ was identified between the metal-depleted and metalreplete samples by one-way analysis of variance (ANOVA) with a Dunnett's posttest. More in-depth investigations of this finding are under way. Together, these data suggest that metal withholding and CP increases the tolerance of PA14 to polymyxin B.

\section{DISCUSSION}

In the current work, we systematically evaluated the contributions of $\mathrm{Fe}, \mathrm{Zn}$, and $\mathrm{Mn}$ limitation to the proteomic response of $P$. aeruginosa to $\mathrm{CP}$ in a chemically defined 
medium. We previously demonstrated an Fe starvation response to CP (10) but reasoned that a broader physiological response was necessary to maintain metal homeostasis in response to $\mathrm{CP}$ multimetal withholding. Our results demonstrate that the response of $P$. aeruginosa to $C P$ is not simply an additive response to Fe and $\mathrm{Zn}$ withholding. Moreover, we identified CP-dependent induction of membrane modification proteins that appear to afford polymyxin B tolerance. Because this response was not observed following depletion of any single metal, we hypothesize that it is dependent on a general depletion of transition metals by CP. Consequently, this work demonstrates that multimetal sequestration elicits distinct effects compared to individual metal depletion on the physiology and virulence capacity of a human pathogen.

A goal of our study was to determine how sequestration of $\mathrm{Fe}, \mathrm{Zn}$, and Mn contributes to the response of $P$. aeruginosa to CP. Thus, in our analyses, specific responses to single-metal limitation were compared to the response to $\mathrm{CP}$ multimetal withholding. This analysis revealed that the CP-induced Fe starvation response was markedly incomplete compared to the Fe starvation response observed in Fe-depleted medium. For example, CP induced upregulation of Fe acquisition proteins; but, many Fe-containing metabolic proteins, which are normally downregulated by the PrrF sRNAs upon Fe limitation (51), were not significantly affected by CP treatment. Consistent with our findings, a previous transcriptomic study of the response of $P$. aeruginosa to CP showed decreased expression of phenazine biosynthesis genes and increased expression of pyoverdine biosynthesis genes but no change in the expression of PrrF-responsive TCA cycle genes (37). This earlier study attributed many of these changes to $\mathrm{Zn}$ limitation because the $\mathrm{Fe}(\mathrm{II})$-withholding ability of $\mathrm{CP}$ was not yet accepted, leading to the proposal that a subset of Fe-regulated genes could also be responsive to other metals (37). Nevertheless, our previous proteomics study of Fe-limited PAO1 demonstrated that decreased expression of phenazine biosynthesis proteins and increased expression of pyoverdine biosynthesis proteins occurred in a strictly Fe-dependent manner, suggesting that CP induces some, but not all, of the prototypical Fe starvation responses in $P$. aeruginosa (10). The current study further supports that decreased expression of phenazine biosynthesis proteins and increased expression of pyoverdine biosynthesis proteins result from Fe limitation. The origin or origins of the incomplete Fe starvation response to $\mathrm{CP}$ are unclear. We currently speculate that it results from a tiered response to different levels of Fe limitation similar to what was found for the Bacillus subtilis Zn starvation response (64). For example, the Zn starvation response that is elicited by CP treatment may mask the activation of specific Fe starvation pathways, resulting in a distinct Fe starvation response following $\mathrm{CP}$ treatment compared to Fe limitation. More work is needed to understand the observed differences in Fe starvation responses between these two conditions.

We also observed a robust $\mathrm{Zn}$ starvation response to $\mathrm{CP}$, evidenced by the upregulation of multiple $\mathrm{Zn}$ (II) uptake systems by PA14. In contrast to the incomplete CPinduced Fe starvation response described above, the $\mathrm{Zn}$ starvation response elicited by $C P$ was comparable to that caused by $\mathrm{Zn}$ limitation, suggesting a robust response to $\mathrm{Zn}$ (II) withholding by CP. Notably, the Zn starvation response is induced in the absence of a decrease in cell-associated $Z n$ during CP treatment $(10,45)$. This observation is consistent with previous reports that $\mathrm{CP}$ treatment results in metal starvation responses without changes to the corresponding cell-associated metal concentrations $(65,66)$. For instance, CP was found to exert antimicrobial activity and induce a Zn starvation response in Candida albicans without decreasing cell-associated $\mathrm{Zn}$ (65). In Acinetobacter baumannii, the $\mathrm{Cu}$ uptake protein OprC was downregulated, and a $\mathrm{Cu}$ storage protein was upregulated, indicating a $\mathrm{Cu}$ starvation response to $\mathrm{CP}$ without a change in cell-associated $\mathrm{Cu}$ (66). One reason for these differences is that the measurements provide the total cellular metal content, which includes both labile metal pools that can be sensed by the cell as well as kinetically inaccessible (e.g., stored) metal pools. Together, these data indicate that a decrease in cell-associated metal content is not always a reliable indicator of how pathogens respond to multimetal withholding. 
In addition to the $\mathrm{Zn}$ starvation response, $\mathrm{CP}$ treatment and $\mathrm{Zn}$ limitation both resulted in an unexpected increase in $\mathrm{Zn}$ (II)-dependent proteases. Further analyses showed that $\mathrm{CP}$ treatment and $\mathrm{Zn}$ limitation decreased LasB activity in culture supernatants, aligning with previous studies $(24,26,38,67)$. Because of the intracellular increase in abundance of the secreted proteins, we initially hypothesized that a decrease in protease secretion may contribute to the observed decrease in LasB activity. However, we observed no increase in LasB activity in the cell lysate and little change in protein abundance or in transcript levels for the Xcp and Hxc T2SS systems that export these proteases, although it is possible that protease secretion is reduced by an unknown mechanism. A previous study demonstrated that $\mathrm{CP}$ chelated $\mathrm{Zn}(\mathrm{II})$ from proteases when the supernatant was treated with $\mathrm{CP}$ (38). Further work will be needed to determine the mechanism of decreased protease during $\mathrm{Zn}$ limitation and to determine the mechanism of decreased protease activity during $\mathrm{CP}$ treatment of cultures.

Recently, CP was shown to induce a multimetal starvation response in A. baumannii (66). In addition to the induction of siderophores and other Fe uptake systems, the authors proposed a dual regulatory system that responds to $\mathrm{Zn}$ withholding and flavin mononucleotide (FMN) concentration to induce a $\mathrm{Zn}(\mathrm{II})$-independent enzyme that maintains flavin biosynthesis during $\mathrm{Zn}$ limitation. Flavin biosynthesis is necessary for the production of flavodoxins and FMNs, which can act as Fe-independent substitutes for ferredoxins and cofactor Fe-independent homologs, respectively. Our recent work identified potential crosstalk between the Fe and $\mathrm{Zn}$ homeostasis systems of $P$. aeruginosa (51), but this crosstalk was not evident in the current study, possibly due to the 20-fold lower Fe concentration used for the proteomics experiments. Thus, it remains unclear how much the interactions of distinct metal regulatory systems contribute to the response of $P$. aeruginosa to $C P$.

We also identified what appears to be a multimetal limitation response following $\mathrm{CP}$ treatment with the induction of the PmrAB two-component regulatory system and its targets ArnA, ArnB, and SpeE2 (Fig. 2 and 5). PmrAB activation of the arn operon results in the addition of aminoarabinose modifications to lipid $A$, resulting in increased tolerance to CAMPs, such as colistin and polymyxin $B$. The PmrAB regulon is known to be induced by $\mathrm{Mg}(\mathrm{II})$ and $\mathrm{Ca}$ (II) limitation $(59,68)$. Here, we provide evidence that this operon is more generally responsive to low concentrations of transition metal limitation caused by CP. A previous study demonstrated that extracellular DNA binds cations and induces resistance to CAMPs through the activity of PmrAB-regulated proteins (69), further supporting the conclusion that a more generalized low-cation environment can initiate the PmrAB pathway. We provide evidence that both $\mathrm{CP}$ treatment and transition metal depletion results in increased tolerance to polymyxin $B$. While we did not address the mechanism in this study, the observed upregulation of ArnA and ArnB suggests that increased tolerance occurs through the addition of aminoarabinose to lipid $A(59,61)$. This modification is highly relevant in the clinical setting as aminoarabinose modification of lipid $A$ is commonly observed in polymyxin-tolerant $P$. aeruginosa isolates $(70,71)$. Nebulized colistin is commonly used to reduce $P$. aeruginosa burdens in the lungs of CF patients (72-74). Our results suggest that CP released during the inflammatory response in the CF lung may promote $P$. aeruginosa to tolerate this treatment. CP also decreased activity of lipid A biosynthesis proteins in Helicobacter pylori, resulting in altered lipid A structure, which led to increased biofilm production and reduced growth inhibitory activity of CP (75). It is possible that changes to lipid A are a widespread response of Gram-negative bacteria to $C P$.

In closing, the results from this proteomics study provide new insights into host-pathogen interactions by systematically evaluating how multimetal withholding by CP impacts $P$. aeruginosa physiology. This work demonstrates that the response of $P$. aeruginosa to metal withholding by $C P$ is not the additive response of individual metal starvation responses. Moreover, metal starvation responses are linked to virulence regulatory networks in many pathogens, and the current work highlights that response of $P$. aeruginosa to multimetal limitation elicits several changes in virulence-related processes. Thus, this 
investigation broadens our understanding of how nutritional immunity impacts the pathogenic potential of an important opportunistic bacterial pathogen.

\section{MATERIALS AND METHODS}

Growth media and conditions. P. aeruginosa strain PA14 was used for all experiments. Throughout the paper, we have used the locus tags for PAO1 instead of PA14 when gene names are not available for ease of reading and comparison to the literature. PA14 was grown as previously described in chemically defined medium (CDM). CDM was made as previously described $(10,39)$ with some modifications (Table S4 in the supplemental material). Briefly, the medium was made without added $\mathrm{Mg}(\mathrm{II})$ and was then aliquoted and stored at $-80^{\circ} \mathrm{C}$. Before an experiment, the medium was thawed and supplemented with $0.1 \mu \mathrm{M} \mathrm{NiCl}_{2}, 0.1 \mu \mathrm{M} \mathrm{CuCl}_{2}, 5 \mu \mathrm{M} \mathrm{FeSO}_{4}, 6 \mu \mathrm{M} \mathrm{ZnCl}_{2}, 0.3 \mu \mathrm{M} \mathrm{MnCl}_{2}, 2 \mathrm{mM} \mathrm{MgSO}$, and $2 \mathrm{mM} \mathrm{CaCl}_{2}$ to afford metal-replete CDM. Calprotectin (CP; $10 \mu \mathrm{M}$ final concentration) was added to CDM where indicated. Metal-depleted CDM was made by supplementing with only $\mathrm{NiCl}_{2}, \mathrm{CuCl}_{2}, \mathrm{MgSO}_{4}$, and $\mathrm{CaCl}_{2}$. Fedepleted, Zn-depleted, and Mn-depleted CDM were made by not adding Fe, $\mathrm{Zn}$, or Mn, respectively, to the CDM. Low-Mg CDM was made by adding $20 \mu \mathrm{M} \mathrm{MgSO}_{4}$ instead of $2 \mathrm{mM} \mathrm{MgSO}_{4}$ to metal-replete CDM. Cultures for all experiments were inoculated to an optical density at $600 \mathrm{~nm}\left(\mathrm{OD}_{600}\right)$ of 0.05 and grown for $8 \mathrm{~h}$ with shaking at $250 \mathrm{rpm}$ at $37^{\circ} \mathrm{C}$. Except for the proteomics experiment, all experiments were repeated at least three times to ensure reproducibility.

Calprotectin purification. CP was purified as previously described (76). Protein aliquots were stored in $20 \mathrm{mM}$ HEPES, $100 \mathrm{mM} \mathrm{NaCl}$, and $5 \mathrm{mM}$ dithiothreitol (DTT) ( $\mathrm{pH} \mathrm{8.0)}$ at $-80^{\circ} \mathrm{C}$. Aliquots were thawed only once before use and buffer exchanged three times into $20 \mathrm{mM}$ Tris and $100 \mathrm{mM} \mathrm{NaCl}(\mathrm{pH} 7.5)$ using presterilized $10 \mathrm{kDa}$ molecular weight cutoff (MWCO) spin concentrators (Amicon). Protein concentrations were determined by $A_{280}$ using the calculated extinction coefficient of the CP heterodimer $\left(\varepsilon_{280}=\right.$ $18,540 \mathrm{M}^{-1} \mathrm{~cm}^{-1}$ ) obtained from the online ExPASy ProtParam tool.

Quantitative label-free proteomics. Two independent proteomics experiments were performed each with five biological replicates. The medium for both experiments was prepared as described above as a single batch and inoculated with the same five overnight cultures, and samples were collected for both experiments at the same time to limit variability. For the first experiment, PA14 was grown in metal-replete CDM with and without $10 \mu \mathrm{M} \mathrm{CP}$. For the second experiment, PA14 was grown in metalreplete, Fe-depleted, Mn-depleted, Zn-depleted, and metal-depleted CDM. Quantitative label-free proteomics was performed using a Waters nanoACQUITY ultraperformance liquid chromatography (UPLC) system coupled to a Thermo Orbitrap Fusion Lumos Tribrid mass spectrometer similar to as previously described with modifications (46-48). A full description of the mass spectrometry-based experimental methodology is provided in the supplemental materials. Gene function and pathway analysis was conducted using information from the Pseudomonas genome database (77), the Pseudomonas metabolome database (78), and the STRING database (49).

Network analysis. Network analysis was performed using the STRING database, version 10.5 (49). Corresponding PAO1 accession numbers were used as the database is limited to the PAO1 strain. The network was downloaded from STRING and further analyzed using Cytoscape (79). The Omics Viewer app was used within Cytoscape to incorporate proteomics expression data into networks (80).

AntR reporter assay. PA14/PantR-'lac $Z^{-S D}$ was generated previously (10). Cultures were grown in metal-replete CDM with or without $10 \mu \mathrm{M} \mathrm{CP}$ as described above. $\beta$-Galactosidase activity was measured as previously described (81). Briefly, bacterial growth was measured by $\mathrm{OD}_{600}$, and cells were harvested by centrifugation and resuspended in potassium phosphate buffer (50 mM, pH 7.0). Cells were diluted 1:10 in Z buffer $\left(60 \mathrm{mM} \mathrm{Na}_{2} \mathrm{HPO}_{4}, 35 \mathrm{mM} \mathrm{NaH} \mathrm{PO}_{4}, 1 \mathrm{mM} \mathrm{KCl}, 100 \mathrm{mM} \mathrm{MgSO}\right.$, and $50 \mathrm{mM}$ $\beta$-mercaptoethanol) and lysed using chloroform and $0.1 \%$ SDS. The enzyme reaction was started using $o$-nitrophenyl- $\beta$-D-galactopyranoside (ONPG, $4 \mathrm{mg} / \mathrm{ml}$ ) dissolved in potassium phosphate buffer and stopped using sodium carbonate $(1 \mathrm{M})$. The quenched reaction was centrifuged to remove cell debris, and the supernatant absorbance was read at $A_{420}, \beta$-Galactosidase activity was calculated into Miller units $(\mathrm{MU})$ using the following equation: $\mathrm{MU}=\left(1,000 \times A_{420}\right) /($ time $[\mathrm{min}] \times$ culture volume $[\mathrm{ml}] \times$ $\left.\mathrm{OD}_{600}\right)$.

Real-time PCR. Five cultures of PA14 were grown as described above in metal-replete CDM, Fedepleted, Mn-depleted, Zn-depleted, and metal-depleted CDM, and in metal-replete CDM in the presence of CP. Real-time PCR (RT-PCR) was performed as previously described (21). Briefly, cell pellets were stored in RNAlater at $-80^{\circ} \mathrm{C}$. RNA was extracted using a Qiagen RNeasy kit, cDNA was synthesized, and RT-PCR was performed using TaqMan reagents (Roche) and a StepOnePlus system (Thermo Fisher). Relative expression was determined using the $\Delta \Delta C_{T}$ method. Expression was normalized to the $16 \mathrm{~S}$ ribosomal gene. Primers and probes used are listed in Table S5.

Azocasein protease activity assay. Five biological replicates of PA14 were grown as described above. After $8 \mathrm{~h}$ of growth, cultures were centrifuged at $16,000 \times g$ for $10 \mathrm{~min}$. The supernatants were sterile filtered using $0.2-\mu \mathrm{m}$ pore size filters (Costar) and stored at $4^{\circ} \mathrm{C}$ overnight. Cell pellets were lysed using BugBuster (Novagen) according to instructions. LasB activity was quantified as previously described (82). Briefly, $20 \mu \mathrm{l}$ of supernatant was added to $0.5 \mathrm{ml}$ of the $0.3 \%$ azocasein solution ( $50 \mathrm{mM}$ Tris- $\mathrm{HCl}[\mathrm{pH} 7.2]$ and $0.5 \mathrm{mM} \mathrm{CaCl}_{2}$ buffer supplemented with or without $10 \mu \mathrm{M} \mathrm{ZnCl}_{2}$ ) and incubated for $30 \mathrm{~min}$ at $37^{\circ} \mathrm{C}$. The reaction was stopped with $0.5 \mathrm{ml}$ of $10 \%$ trichloroacetic acid. The quenched reaction mixture was centrifuged at $16,000 \times g$ for $20 \mathrm{~min}$, and the supernatant absorbance was read at $400 \mathrm{~nm}$ using a Biotek Synergy HT plate reader. One unit of enzyme activity changes the $A_{400}$ by 0.01 . The enzyme activity was normalized to $\mathrm{OD}_{600}$. 
Minimal bactericidal concentration assay. Three biological replicates of PA14 were grown as described above in metal-replete CDM, metal-depleted, and low-Mg CDM, and in metal-replete CDM in the presence of $10 \mu \mathrm{M} \mathrm{CP}$. After $8 \mathrm{~h}$ of growth, the cultures were centrifuged, and the cells were resuspended in phosphate-buffered saline (PBS). The $\mathrm{OD}_{600}$ was measured, and PBS was inoculated to an $\mathrm{OD}_{600}$ of 0.05 , which was subsequently diluted 1:10 into metal-replete $\mathrm{CDM}$ with no $\mathrm{CaCl}_{2}$ supplementation. The 1:10 dilution was used to inoculate $1 \times 10^{5} \mathrm{CFU}$ into $2 \mathrm{ml}$ of metal-replete $\mathrm{CDM}$ with no $\mathrm{CaCl}_{2}$ supplementation containing $0,1,2,4,8,16,32$, or $64 \mathrm{mg} /$ liter polymyxin B. Serial dilutions of the inoculum were performed and plated on Pseudomonas isolation agar (PIA) and incubated overnight to ensure inoculum was at $1 \times 10^{5} \mathrm{CFU} / \mathrm{ml}$. Cultures were incubated for $18 \mathrm{~h}$ at $37^{\circ} \mathrm{C}$. After growth, $10 \mu \mathrm{l}$ of culture was spotted onto PIA, and the plates were incubated overnight at $37^{\circ} \mathrm{C}$.

Data availability. The mass spectrometry proteomics data have been deposited to the ProteomeXchange Consortium via the PRIDE (83) partner repository with the dataset identifier PXD027638.

\section{SUPPLEMENTAL MATERIAL}

Supplemental material is available online only.

SUPPLEMENTAL FILE 1, XLSX file, 0.1 MB.

SUPPLEMENTAL FILE 2, XLSX file, 0.1 MB.

SUPPLEMENTAL FILE 3, PDF file, $0.5 \mathrm{MB}$.

\section{ACKNOWLEDGMENTS}

This work was supported by the NIH (R01 GM126376 to E.M.N. and A.G.O;; T32 Al095190 to C.E.N.) and the University of Maryland School of Pharmacy Mass Spectrometry Center (SOP1841-IQB2014 to M.A.K.). E.M.Z. is a recipient of a National Science Foundation Graduate Research Fellowship and a Whitaker Health Science Fund Fellowship.

\section{REFERENCES}

1. Weinberg ED. 1975. Nutritional immunity. Host's attempt to withold iron from microbial invaders. JAMA 231:39-41. https://doi.org/10.1001/jama .1975.03240130021018.

2. Hood MI, Skaar EP. 2012. Nutritional immunity: transition metals at the pathogen-host interface. Nat Rev Microbiol 10:525-537. https://doi.org/ 10.1038/nrmicro2836.

3. Kehl-Fie TE, Skaar EP. 2010. Nutritional immunity beyond iron: a role for manganese and zinc. Curr Opin Chem Biol 14:218-224. https://doi.org/10 .1016/j.cbpa.2009.11.008.

4. Zygiel EM, Nolan EM. 2018. Transition metal sequestration by the hostdefense protein calprotectin. Annu Rev Biochem 87:621-643. https://doi .org/10.1146/annurev-biochem-062917-012312

5. Kehl-Fie TE, Chitayat S, Hood MI, Damo S, Restrepo N, Garcia C, Munro KA, Chazin WJ, Skaar EP. 2011. Nutrient metal sequestration by calprotectin inhibits bacterial superoxide defense, enhancing neutrophil killing of Staphylococcus aureus. Cell Host Microbe 10:158-164. https://doi.org/10 .1016/j.chom.2011.07.004.

6. Bianchi M, Niemiec MJ, Siler U, Urban CF, Reichenbach J. 2011. Restoration of anti-Aspergillus defense by neutrophil extracellular traps in human chronic granulomatous disease after gene therapy is calprotectin-dependent. J Allergy Clin Immunol 127:1243-1252. https://doi.org/10.1016/j jaci.2011.01.021.

7. Corbin BD, Seeley EH, Raab A, Feldmann J, Miller MR, Torres VJ, Anderson KL, Dattilo BM, Dunman PM, Gerads R, Caprioli RM, Nacken W, Chazin WJ, Skaar EP. 2008. Metal chelation and inhibition of bacterial growth in tissue abscesses. Science 319:962-965. https://doi.org/10.1126/science.1152449.

8. Urban CF, Ermert D, Schmid M, Abu-Abed U, Goosmann C, Nacken W, Brinkmann V, Jungblut PR, Zychlinsky A. 2009. Neutrophil extracellular traps contain calprotectin, a cytosolic protein complex involved in host defense against Candida albicans. PLoS Pathog 5:e1000639. https://doi .org/10.1371/journal.ppat.1000639.

9. Damo SM, Kehl-Fie TE, Sugitani N, Holt ME, Rathi S, Murphy WJ, Zhang Y, Betz C, Hench L, Fritz G, Skaar EP, Chazin WJ. 2013. Molecular basis for manganese sequestration by calprotectin and roles in the innate immune response to invading bacterial pathogens. Proc Natl Acad Sci U S A 110: 3841-3846. https://doi.org/10.1073/pnas.1220341110.

10. Zygiel EM, Nelson CE, Brewer LK, Oglesby-Sherrouse AG, Nolan EM. 2019. The human innate immune protein calprotectin induces iron starvation responses in Pseudomonas aeruginosa. J Biol Chem 294:3549-3562. https:// doi.org/10.1074/jbc.RA118.006819.
11. Antelo GT, Vila AJ, Giedroc DP, Capdevila DA. 2021. Molecular evolution of transition metal bioavailability at the host-pathogen interface. Trends Microbiol 29:441-457. https://doi.org/10.1016/j.tim.2020.08.001.

12. Posey JE, Gherardini FC. 2000. Lack of a role for iron in the Lyme disease pathogen. Science 288:1651-1653. https://doi.org/10.1126/science.288 .5471 .1651 .

13. Lisher JP, Giedroc DP. 2013. Manganese acquisition and homeostasis at the host-pathogen interface. Front Cell Infect Microbiol 3:91. https://doi .org/10.3389/fcimb.2013.00091.

14. Nguyen AT, Oglesby-Sherrouse AG. 2015. Spoils of war: iron at the crux of clinical and ecological fitness of Pseudomonas aeruginosa. Biometals 28: 433-443. https://doi.org/10.1007/s10534-015-9848-6.

15. Reinhart AA, Oglesby-Sherrouse AG. 2016. Regulation of Pseudomonas aeruginosa virulence by distinct iron sources. Genes (Basel) 7:126. https:// doi.org/10.3390/genes7120126.

16. Ochsner UA, Vasil Al, Vasil ML. 1995. Role of the ferric uptake regulator of Pseudomonas aeruginosa in the regulation of siderophores and exotoxin A expression: purification and activity on iron-regulated promoters. J Bacteriol 177:7194-7201. https://doi.org/10.1128/jb.177.24.7194-7201.1995.

17. Wilderman PJ, Sowa NA, FitzGerald DJ, FitzGerald PC, Gottesman S, Ochsner UA, Vasil ML. 2004. Identification of tandem duplicate regulatory small RNAs in Pseudomonas aeruginosa involved in iron homeostasis. Proc Natl Acad Sci U S A 101:9792-9797. https://doi.org/10.1073/pnas .0403423101 .

18. Oglesby AG, Farrow JM, III, Lee JH, Tomaras AP, Greenberg EP, Pesci EC, Vasil ML. 2008. The influence of iron on Pseudomonas aeruginosa physiology: a regulatory link between iron and quorum sensing. J Biol Chem 283:15558-15567. https://doi.org/10.1074/jbc.M707840200.

19. Masse E, Gottesman S. 2002. A small RNA regulates the expression of genes involved in iron metabolism in Escherichia coli. Proc Natl Acad Sci U S A 99:4620-4625. https://doi.org/10.1073/pnas.032066599.

20. Reinhart AA, Powell DA, Nguyen AT, O'Neill M, Djapgne L, Wilks A, Ernst RK, Oglesby-Sherrouse AG. 2015. The prrF-encoded small regulatory RNAs are required for iron homeostasis and virulence of Pseudomonas aeruginosa. Infect Immun 83:863-875. https://doi.org/10.1128/IAI.02707-14.

21. Reinhart AA, Nguyen AT, Brewer LK, Bevere J, Jones JW, Kane MA, Damron FH, Barbier M, Oglesby-Sherrouse AG. 2017. The Pseudomonas aeruginosa PrrF small RNAs regulate iron homeostasis during acute murine lung infection. Infect Immun 85:e00764-16. https://doi.org/10.1128/ IAI.00764-16. 
22. Ellison ML, Farrow JM, III, Parrish W, Danell AS, Pesci EC. 2013. The transcriptional regulator Np20 is the zinc uptake regulator in Pseudomonas aeruginosa. PLoS One 8:e75389. https://doi.org/10.1371/journal.pone .0075389 .

23. Pederick VG, Eijkelkamp BA, Begg SL, Ween MP, McAllister LJ, Paton JC, McDevitt CA. 2015. ZnuA and zinc homeostasis in Pseudomonas aeruginosa. Sci Rep 5:13139. https://doi.org/10.1038/srep13139.

24. D'Orazio M, Mastropasqua MC, Cerasi M, Pacello F, Consalvo A, Chirullo B, Mortensen B, Skaar EP, Ciavardelli D, Pasquali P, Battistoni A. 2015. The capability of Pseudomonas aeruginosa to recruit zinc under conditions of limited metal availability is affected by inactivation of the ZnuABC transporter. Metallomics 7:1023-1035. https://doi.org/10.1039/c5mt00017c.

25. Lhospice S, Gomez NO, Ouerdane L, Brutesco C, Ghssein G, Hajjar C, Liratni A, Wang S, Richaud P, Bleves S, Ball G, Borezee-Durant E, Lobinski R, Pignol D, Arnoux P, Voulhoux R. 2017. Pseudomonas aeruginosa zinc uptake in chelating environment is primarily mediated by the metallophore pseudopaline. Sci Rep 7:17132. https://doi.org/10.1038/s41598 -017-16765-9.

26. Mastropasqua MC, D'Orazio M, Cerasi M, Pacello F, Gismondi A, Canini A, Canuti L, Consalvo A, Ciavardelli D, Chirullo B, Pasquali P, Battistoni A. 2017. Growth of Pseudomonas aeruginosa in zinc poor environments is promoted by a nicotianamine-related metallophore. Mol Microbiol 106: 543-561. https://doi.org/10.1111/mmi.13834.

27. Hassan MT, van der Lelie D, Springael D, Römling U, Ahmed N, Mergeay M. 1999. Identification of a gene cluster, czr, involved in cadmium and zinc resistance in Pseudomonas aeruginosa. Gene 238:417-425. https:// doi.org/10.1016/s0378-1119(99)00349-2.

28. Salusso A, Raimunda D. 2017. Defining the roles of the cation diffusion facilitators in $\mathrm{Fe}^{2+} / \mathrm{Zn}^{2+}$ homeostasis and establishment of their participation in virulence in Pseudomonas aeruginosa. Front Cell Infect Microbiol 7:84. https://doi.org/10.3389/fcimb.2017.00084.

29. Ducret V, Gonzalez MR, Leoni S, Valentini M, Perron K. 2020. The CzcCBA efflux system requires the CadA P-type ATPase for timely expression upon zinc excess in Pseudomonas aeruginosa. Front Microbiol 11:911. https://doi.org/10.3389/fmicb.2020.00911.

30. Haritha A, Rodrigue A, Mohan PM. 2008. A comparative analysis of metal transportomes from metabolically versatile Pseudomonas. BMC Res Notes 1:88. https://doi.org/10.1186/1756-0500-1-88.

31. Lee SJ, Kim DJ, Kim HS, Lee BI, Yoon HJ, Yoon JY, Kim KH, Jang JY, Im HN, An DR, Song JS, Kim HJ, Suh SW. 2011. Crystal structures of Pseudomonas aeruginosa guanidinobutyrase and guanidinopropionase, members of the ureohydrolase superfamily. J Struct Biol 175:329-338. https://doi.org/ 10.1016/j.jsb.2011.05.002.

32. Hassett DJ, Schweizer HP, Ohman DE. 1995. Pseudomonas aeruginosa $\operatorname{sod} A$ and sodB mutants defective in manganese- and iron-cofactored superoxide dismutase activity demonstrate the importance of the ironcofactored form in aerobic metabolism. J Bacteriol 177:6330-6337. https://doi.org/10.1128/jb.177.22.6330-6337.1995.

33. Quintana J, Novoa-Aponte L, Arguello JM. 2017. Copper homeostasis networks in the bacterium Pseudomonas aeruginosa. J Biol Chem 292: 15691-15704. https://doi.org/10.1074/jbc.M117.804492.

34. Cowley ES, Kopf SH, LaRiviere A, Ziebis W, Newman DK. 2015. Pediatric cystic fibrosis sputum can be chemically dynamic, anoxic, and extremely reduced due to hydrogen sulfide formation. mBio 6:e00767. https://doi .org/10.1128/mBio.00767-15.

35. Lyczak JB, Cannon CL, Pier GB. 2002. Lung infections associated with cystic fibrosis. Clin Microbiol Rev 15:194-222. https://doi.org/10.1128/ CMR.15.2.194-222.2002.

36. Wilkinson MM, Busuttil A, Hayward C, Brock DJ, Dorin JR, Van Heyningen V. 1988. Expression pattern of two related cystic fibrosis-associated calcium-binding proteins in normal and abnormal tissues. J Cell Sci 91: 221-230. https://doi.org/10.1242/jcs.91.2.221.

37. Wakeman CA, Moore JL, Noto MJ, Zhang Y, Singleton MD, Prentice BM, Gilston BA, Doster RS, Gaddy JA, Chazin WJ, Caprioli RM, Skaar EP. 2016. The innate immune protein calprotectin promotes Pseudomonas aeruginosa and Staphylococcus aureus interaction. Nat Commun 7:11951. https://doi.org/10.1038/ncomms11951.

38. Vermilyea DM, Crocker AW, Gifford AH, Hogan DA. 2021. Calprotectinmediated zinc chelation inhibits Pseudomonas aeruginosa protease activity in cystic fibrosis sputum. J Bacteriol 203:e0010021. https://doi.org/10 .1128/JB.00100-21.

39. Nakashige TG, Zygiel EM, Drennan CL, Nolan EM. 2017. Nickel sequestration by the host-defense protein human calprotectin. J Am Chem Soc 139:8828-8836. https://doi.org/10.1021/jacs.7b01212.
40. Gray RD, Duncan A, Noble D, Imrie M, O'Reilly DS, Innes JA, Porteous DJ, Greening AP, Boyd AC. 2010. Sputum trace metals are biomarkers of inflammatory and suppurative lung disease. Chest 137:635-641. https:// doi.org/10.1378/chest.09-1047.

41. Reid DW, Lam QT, Schneider H, Walters EH. 2004. Airway iron and ironregulatory cytokines in cystic fibrosis. Eur Respir J 24:286-291. https://doi .org/10.1183/09031936.04.00104803.

42. Reid DW, Withers NJ, Francis L, Wilson JW, Kotsimbos TC. 2002. Iron deficiency in cystic fibrosis: relationship to lung disease severity and chronic Pseudomonas aeruginosa infection. Chest 121:48-54. https://doi.org/10 .1378/chest.121.1.48.

43. Gray RD, Imrie M, Boyd AC, Porteous D, Innes JA, Greening AP. 2010. Sputum and serum calprotectin are useful biomarkers during CF exacerbation. J Cystic Fibrosis 9:193-198. https://doi.org/10.1016/j.jcf.2010.01.005.

44. Barth AL, Pitt TL. 1996. The high amino-acid content of sputum from cystic fibrosis patients promotes growth of auxotrophic Pseudomonas aeruginosa. J Med Microbiol 45:110-119. https://doi.org/10.1099/00222615-45-2-110.

45. Zygiel EM, Obisesan AO, Nelson CE, Oglesby AG, Nolan EM. 2021. Heme protects Pseudomonas aeruginosa and Staphylococcus aureus from calprotectin-induced iron starvation. J Biol Chem 296:100160. https://doi.org/10 .1074/jbc.RA120.015975.

46. Brewer LK, Huang W, Hackert BJ, Kane MA, Oglesby AG. 2020. Static growth promotes PrrF and 2-alkyl-4(1H)-quinolone regulation of type $\mathrm{VI}$ secretion protein expression in Pseudomonas aeruginosa. J Bacteriol 202: e00416-20. https://doi.org/10.1128/JB.00416-20.

47. Defnet AE, Huang W, Polischak S, Yadav SK, Kane MA, Shapiro P, Deshpande DA. 2019. Effects of ATP-competitive and function-selective ERK inhibitors on airway smooth muscle cell proliferation. FASEB J 33: 10833-10843. https://doi.org/10.1096/fj.201900680R.

48. Kim D, Chen R, Sheu M, Kim N, Kim S, Islam N, Wier EM, Wang G, Li A, Park A, Son W, Evans B, Yu V, Prizmic VP, Oh E, Wang Z, Yu J, Huang W, Archer NK, Hu Z, Clemetson N, Nelson AM, Chien A, Okoye GA, Miller LS, Ghiaur G, Kang S, Jones JW, Kane MA, Garza LA. 2019. Noncoding dsRNA induces retinoic acid synthesis to stimulate hair follicle regeneration via TLR3. Nat Commun 10:2811. https://doi.org/10.1038/s41467-019-10811-y.

49. Szklarczyk D, Morris JH, Cook H, Kuhn M, Wyder S, Simonovic M, Santos A, Doncheva NT, Roth A, Bork P, Jensen LJ, von Mering C. 2017. The STRING database in 2017: quality-controlled protein-protein association networks, made broadly accessible. Nucleic Acids Res 45:D362-D368. https://doi.org/10.1093/nar/gkw937.

50. Ochsner UA, Wilderman PJ, Vasil Al, Vasil ML. 2002. GeneChip expression analysis of the iron starvation response in Pseudomonas aeruginosa: identification of novel pyoverdine biosynthesis genes. Mol Microbiol 45: 1277-1287. https://doi.org/10.1046/j.1365-2958.2002.03084.x.

51. Nelson CE, Huang W, Brewer LK, Nguyen AT, Kane MA, Wilks A, OglesbySherrouse AG. 2019. Proteomic analysis of the Pseudomonas aeruginosa iron starvation response reveals PrrF small regulatory RNA-dependent iron regulation of twitching motility, amino acid metabolism, and zinc homeostasis proteins. J Bacteriol 201:e00754-18. https://doi.org/10.1128/JB .00754-18.

52. Hood MI, Mortensen BL, Moore JL, Zhang Y, Kehl-Fie TE, Sugitani N, Chazin WJ, Caprioli RM, Skaar EP. 2012. Identification of an Acinetobacter baumannii zinc acquisition system that facilitates resistance to calprotectin-mediated zinc sequestration. PLoS Pathog 8:e1003068. https://doi .org/10.1371/journal.ppat.1003068.

53. Djapgne L, Panja S, Brewer LK, Gans JH, Kane MA, Woodson SA, OglesbySherrouse AG. 2018. The Pseudomonas aeruginosa PrrF1 and PrrF2 small regulatory RNAs promote 2-alkyl-4-quinolone production through redundant regulation of the antR mRNA. J Bacteriol 200:e00704-17. https://doi .org/10.1128/JB.00704-17.

54. McPhee JB, Lewenza S, Hancock RE. 2003. Cationic antimicrobial peptides activate a two-component regulatory system, $\mathrm{PmrA}-\mathrm{PmrB}$, that regulates resistance to polymyxin $B$ and cationic antimicrobial peptides in Pseudomonas aeruginosa. Mol Microbiol 50:205-217. https://doi.org/10.1046/j .1365-2958.2003.03673.x.

55. Li XH, Lee JH. 2019. Quorum sensing-dependent post-secretional activation of extracellular proteases in Pseudomonas aeruginosa. J Biol Chem 294:19635-19644. https://doi.org/10.1074/jbc.RA119.011047.

56. Bally M, Filloux A, Akrim M, Ball G, Lazdunski A, Tommassen J. 1992. Protein secretion in Pseudomonas aeruginosa: characterization of seven $x c p$ genes and processing of secretory apparatus components by prepilin peptidase. Mol Microbiol 6:1121-1131. https://doi.org/10.1111/j.1365 -2958.1992.tb01550.x. 
57. Ball G, Durand E, Lazdunski A, Filloux A. 2002. A novel type II secretion system in Pseudomonas aeruginosa. Mol Microbiol 43:475-485. https:// doi.org/10.1046/j.1365-2958.2002.02759.x.

58. Guzzo J, Pages JM, Duong F, Lazdunski A, Murgier M. 1991. Pseudomonas aeruginosa alkaline protease: evidence for secretion genes and study of secretion mechanism. J Bacteriol 173:5290-5297. https://doi.org/10.1128/ jb.173.17.5290-5297.1991.

59. Moskowitz SM, Ernst RK, Miller SI. 2004. PmrAB, a two-component regulatory system of Pseudomonas aeruginosa that modulates resistance to cationic antimicrobial peptides and addition of aminoarabinose to lipid A. J Bacteriol 186:575-579. https://doi.org/10.1128/JB.186.2.575-579.2004.

60. Johnson L, Mulcahy H, Kanevets U, Shi Y, Lewenza S. 2012. Surface-localized spermidine protects the Pseudomonas aeruginosa outer membrane from antibiotic treatment and oxidative stress. J Bacteriol 194:813-826. https://doi.org/10.1128/JB.05230-11.

61. Breazeale SD, Ribeiro AA, Raetz CR. 2003. Origin of lipid A species modified with 4-amino-4-deoxy-L-arabinose in polymyxin-resistant mutants of Escherichia coli. An aminotransferase (ArnB) that generates UDP-4-deoxylL-arabinose. J Biol Chem 278:24731-24739. https://doi.org/10.1074/jbc M304043200.

62. Schurek KN, Sampaio JL, Kiffer CR, Sinto S, Mendes CM, Hancock RE. 2009 Involvement of pmrAB and phoPQ in polymyxin $B$ adaptation and inducible resistance in non-cystic fibrosis clinical isolates of Pseudomonas aeruginosa. Antimicrob Agents Chemother 53:4345-4351. https://doi.org/10 1128/AAC.01267-08.

63. Brauner A, Fridman O, Gefen O, Balaban NQ. 2016. Distinguishing between resistance, tolerance and persistence to antibiotic treatment. Nat Rev Microbiol 14:320-330. https://doi.org/10.1038/nrmicro.2016.34.

64. Shin JH, Helmann JD. 2016. Molecular logic of the Zur-regulated zinc deprivation response in Bacillus subtilis. Nat Commun 7:12612. https://doi .org/10.1038/ncomms12612.

65. Besold AN, Gilston BA, Radin JN, Ramsoomair C, Culbertson EM, Li CX, Cormack BP, Chazin WJ, Kehl-Fie TE, Culotta VC. 2018. Role of calprotectin in withholding zinc and copper from Candida albicans. Infect Immun 86: e00779-17. https://doi.org/10.1128/IAl.00779-17.

66. Wang J, Lonergan ZR, Gonzalez-Gutierrez G, Nairn BL, Maxwell CN, Zhang Y, Andreini C, Karty JA, Chazin WJ, Trinidad JC, Skaar EP, Giedroc DP. 2019. Multi-metal restriction by calprotectin impacts de novo flavin biosynthesis in Acinetobacter baumannii. Cell Chem Biol 26:745-755. https://doi.org/10 .1016/j.chembiol.2019.02.011.

67. Mastropasqua MC, Lamont I, Martin LW, Reid DW, D'Orazio M, Battistoni A. 2018. Efficient zinc uptake is critical for the ability of Pseudomonas aeruginosa to express virulence traits and colonize the human lung. J Trace Elem Med Biol 48:74-80. https://doi.org/10.1016/j.jtemb.2018.03.009.

68. Brown MRW, Melling J. 1969. Role of divalent cations in the action of polymyxin B and EDTA on Pseudomonas aeruginosa. Microbiology 59:263-274 . https://doi.org/10.1099/00221287-59-2-263.

69. Lewenza S. 2013. Extracellular DNA-induced antimicrobial peptide resistance mechanisms in Pseudomonas aeruginosa. Front Microbiol 4:21. https://doi.org/10.3389/fmicb.2013.00021.

70. Ernst RK, Yi EC, Guo L, Lim KB, Burns JL, Hackett M, Miller SI. 1999. Specific lipopolysaccharide found in cystic fibrosis airway Pseudomonas aeruginosa. Science 286:1561-1565. https://doi.org/10.1126/science.286.5444 .1561 .

71. Barrow K, Kwon DH. 2009. Alterations in two-component regulatory systems of phoPQ and pmrAB are associated with polymyxin $B$ resistance in clinical isolates of Pseudomonas aeruginosa. Antimicrob Agents Chemother 53:5150-5154. https://doi.org/10.1128/AAC.00893-09.

72. Akkerman-Nijland AM, Grasmeijer F, Kerstjens HAM, Frijlink HW, van der Vaart $\mathrm{H}$, Vonk JM, Hagedoorn P, Rottier BL, Koppelman GH, Akkerman OW. 2020. Colistin dry powder inhalation with the Twincer ${ }^{\mathrm{TM}}$ : an effective and more patient friendly alternative to nebulization. PLoS One 15: e0239658. https://doi.org/10.1371/journal.pone.0239658.

73. Vardakas KZ, Voulgaris GL, Samonis G, Falagas ME. 2018. Inhaled colistin monotherapy for respiratory tract infections in adults without cystic fibrosis: a systematic review and meta-analysis. Int J Antimicrob Agents 51:1-9. https://doi.org/10.1016/j.ijantimicag.2017.05.016.

74. Riethmüller J, Herrmann G, Graepler-Mainka U, Hellwig D, Heuer $\mathrm{HE}_{\text {, }}$ Heyder S, Köster H, Kinder B, Kröger K, Paul K, Poplawska K, Melichar VO, Smaczny C, Mellies U. 2016. Sequential inhalational tobramycin-colistincombination in CF-patients with chronic $P$. aeruginosa colonization-an observational study. Cell Physiol Biochem 39:1141-1151. https://doi.org/ 10.1159/000447821.

75. Gaddy JA, Radin JN, Cullen TW, Chazin WJ, Skaar EP, Trent MS, Algood HMS. 2015. Helicobacter pylori resists the antimicrobial activity of calprotectin via lipid $A$ modification and associated biofilm formation. mBio 6 : e01349-15. https://doi.org/10.1128/mBio.01349-15.

76. Brophy MB, Hayden JA, Nolan EM. 2012. Calcium ion gradients modulate the zinc affinity and antibacterial activity of human calprotectin. J Am Chem Soc 134:18089-18100. https://doi.org/10.1021/ja307974e.

77. Winsor GL, Griffiths EJ, Lo R, Dhillon BK, Shay JA, Brinkman FS. 2016. Enhanced annotations and features for comparing thousands of Pseudomonas genomes in the Pseudomonas genome database. Nucleic Acids Res 44:D646-D653. https://doi.org/10.1093/nar/gkv1227.

78. Huang W, Brewer LK, Jones JW, Nguyen AT, Marcu A, Wishart DS, Oglesby-Sherrouse AG, Kane MA, Wilks A. 2018. PAMDB: a comprehensive Pseudomonas aeruginosa metabolome database. Nucleic Acids Res 46: D575-D580. https://doi.org/10.1093/nar/gkx1061.

79. Su G, Morris JH, Demchak B, Bader GD. 2014. Biological network exploration with Cytoscape 3. Curr Protoc Bioinformatics 47:8.13.1-24. https:// doi.org/10.1002/0471250953.bi0813s47.

80. Legeay M, Doncheva NT, Morris JH, Jensen LJ. 2020. Visualize omics data on networks with Omics Visualizer, a Cytoscape app. F1000Res 9:157. https://doi.org/10.12688/f1000research.22280.2.

81. Sambrook J, Russell D. 2001. Molecular cloning: a laboratory manual, 3rd ed. Cold Spring Harbor Laboratory Press, Cold Spring Harbor, NY.

82. Kessler E, Israel M, Landshman N, Chechick A, Blumberg S. 1982. In vitro inhibition of Pseudomonas aeruginosa elastase by metal-chelating peptide derivatives. Infect Immun 38:716-723. https://doi.org/10.1128/iai.38 .2.716-723.1982.

83. Perez-Riverol $Y$, Csordas A, Bai J, Bernal-Llinares $M$, Hewapathirana $S$, Kundu DJ, Inuganti A, Griss J, Mayer G, Eisenacher M, Pérez E, Uszkoreit J, Pfeuffer J, Sachsenberg T, Yilmaz S, Tiwary S, Cox J, Audain E, Walzer M, Jarnuczak AF, Ternent T, Brazma A, Vizcaíno JA. 2019. The PRIDE database and related tools and resources in 2019: improving support for quantification data. Nucleic Acids Res 47:D442-D450. https://doi.org/10.1093/ nar/gky1106.

84. Benjamini Y, Hochberg Y. 1995. Controlling the false discovery rate: a practical and powerful approach to multiple testing. J R Stat Soc Series B Stat Methodol 57:289-300. https://doi.org/10.1111/j.2517-6161.1995 .tb02031.x. 